\title{
Longevity of protective immune responses induced by a split influenza A (H7N9) vaccine mixed with MF59 adjuvant in BALB/c mice
}

\author{
Huilin Ou ${ }^{1, *}$, Wei $\mathrm{Yao}^{2, *}$, Dongshan $\mathrm{Yu}^{1, *}$, Tianhao Weng ${ }^{1}$, Frederick X.C. Wang ${ }^{3}$, \\ Xiaoxin $\mathrm{Wu}^{1}{ }^{1}$, Haibo $\mathrm{Wu}^{1}{ }^{1}$, Linfang Cheng ${ }^{1}$, Xiangyun $\mathrm{Lu}^{1}$, Nanping $\mathrm{Wu}^{1}{ }^{1}$, Honglin \\ Chen ${ }^{4}$, Lanjuan $\mathrm{Li}^{1}$ and Hangping $\mathrm{Yao}^{1}$ \\ ${ }^{1}$ State Key Laboratory for Diagnosis and Treatment of Infectious Diseases, Collaborative Innovation Center for Diagnosis \\ and Treatment of Infectious Diseases, The First Affiliated Hospital, Zhejiang University School of Medicine, Hangzhou, China \\ ${ }^{2}$ Zhejiang Tianyuan Bio-Pharmaceutical Co., Ltd., Hangzhou, China \\ ${ }^{3}$ Department of Bioengineering, Erik Jonsson School of Engineering and Computer Science, The University of Texas at \\ Dallas, Dallas, Texas, USA \\ ${ }^{4}$ State Key Laboratory for Emerging Infectious Diseases, Carol Yu Centre for Infection, The University of Hong Kong, Hong \\ Kong, China \\ * These authors have contributed equally to this article \\ Correspondence to: Hangping Yao, email: yaohangping@zju.edu.cn
}

Lanjuan Li, email: ljil@zju.edu.cn

Keywords: H7N9, adjuvant vaccine, MF59, immunogenicity, protective immune responses

$\begin{array}{lll}\text { Received: May 26, } 2017 & \text { Accepted: July 29, } 2017 & \text { Published: August 08, } 2017\end{array}$

Copyright: Ou et al. This is an open-access article distributed under the terms of the Creative Commons Attribution License 3.0 (CC BY 3.0), which permits unrestricted use, distribution, and reproduction in any medium, provided the original author and source are credited.

\section{ABSTRACT}

The influenza virus is a serious threat to public health worldwide. A novel avian influenza A (H7N9) virus with a mortality rate of approximately $30 \%$ has been identified as an unusually dangerous virus for humans by the World Health Organization. Pathogenic H7N9 continue to represent a public health concern, and several candidate vaccines are currently in development. We generated candidate H7N9 vaccine strains using reverse genetics, consisting of hemagglutinin and neuraminidase genes derived from a human H7N9 virus and the remaining genes from the PR8 (A/PuertoRico/8/34 (H1N1)) virus. This H7N9 vaccine exhibited superior efficacy when combined with MF59 compared to other adjuvants. Immunized BALB/C mice were followed to determine the duration of the protective immune response. Antibody levels decreased to between one-half and one-eighth of the peak values four months after the final dose of the vaccine. Previously vaccinated mice received an A/Zhejiang/DTID-ZJU01/2013 H7N9 challenge six months post-vaccination, and all remained protected. We also verified that MF59 enhanced the HI, MN, and IgG antibody titers to influenza antigens. The humoral immune response and Th2 cytokine production following influenza challenge was potently induced in the animals that received the split vaccine. Therefore, the split H7N9 influenza vaccine with the MF59 adjuvant could effectively induce antibody production and protect mice from H7N9 virus challenge even after six months.

\section{INTRODUCTION}

Human influenza virus infections with the H7N9 strain were first reported in China in February 2013 [1], and there have been five subsequent waves of infection.
Moreover, total of 1486 laboratory-confirmed cases of human infection with avian influenza A (H7N9) viruses in China, including at least 540 deaths, had been reported to the World Health Organization (WHO) as of May 23, 2017 [2]. The virus can cause rapidly progressive pneumonia, 
often complicated by extrapulmonary disease associated with hypercytokinemia, as well as significant mortality and morbidity [3].

There is minimal pre-existing natural immunity against the new H7N9 avian strain in human populations. Therefore, influenza vaccination, which has been used for more than 60 years, is the primary strategy used for influenza prevention and control. However, several H7 influenza vaccines in clinical development have limited protective efficacy due to the poor immunogenicity of the H7 hemagglutinin (HA) in humans [4-6]. To overcome this challenge, the addition of adjuvants has been used to enhance immune responses.

Currently, vaccine production greatly benefits from molecular biology methods. Particularly useful is the application of reverse genetics, which allows for the removal of pathogenic traits at the plasmid stage to generate novel vaccines and vaccine vectors $[7,8]$. The reassortant candidate virus was constructed using reverse genetics technologies that contains the HA and neuraminidase (NA) glycoproteins of A/Zhejiang/DTIDZJU01/2013 (H7N9), with the remaining 6 genes derived from PR8. It has the advantage of rapid preparation and rapid amplification. Accordingly, we verified that the recombinant clones harbor the desirable characteristics, including lower virulence and transmissibility, as a vaccine strain [9]. Additionally, the oil-in-water adjuvant MF59, which we have paired with our split virus vaccine, has been reported to be safe, well-tolerated, and able to improve the antibody response, permit dose sparing, and lower the antigen dose required to induce protection [10, 11]. Besides, it has been reported the addition of MF59 to split or subunit influenza vaccines can induce much more improvement than the classic immunoadjuvant alum [12].

The vast majority of vaccines are preclinically evaluated for only short-term efficacy over duration of a few weeks. While these vaccines were found to be efficacious shortly after vaccination, it is also vital to assess the duration of the induced protective antibodies following vaccination. Additionally, the immune induction mechanisms of the research vaccine should also be evaluated. In the present study, BALB/c mice were housed in strict isolation for up to six months, and we report the extension of our earlier findings, including the level of immunity following viral challenge in these mice six months after vaccination.

\section{RESULTS}

\section{Evaluation of antibody responses}

Antibody responses in the sera samples of all six groups over the six-month study period are presented in Figure 1. Two weeks after the first vaccination, the geometric mean titers (GMTs) of the hemagglutinin inhibition (HI) titers in the groups immunized with HA antigen (Groups 3 and 5) were all within the range of 10-80, while all microneutralization (MN) titers were below 1:40. The HI, MN, and IgG titers reached a level of significance one month after the first immunization, which was 4 to 16 times higher than the titer of the two week serum sample; this peak persisted at least into the second month. In Groups 4 and 6, the antibody titers reached a relatively high level two weeks after the second immunization, also 1 month based on the first immunization time. For all the groups vaccinated with the HA antigen (Groups 3-6), antibody titers in the four month serum samples had regressed rapidly (two months vs. four months: HI titer, $p=0.003$; $\mathrm{MN}$ titer, $p<0.001$; IgG titer, $p=0.048)$. Antibody titers in the 6-month serum samples were virtually undetectable.

The mean peak antibody titer was substantially higher in the groups that received two-doses of the vaccine (Group 4: HI titer 1:570; MN titer 1:320; IgG titer 1:27549; Group 6: HI titer 1:1140; MN titer 1:718; IgG titer 1:60880), compared with that of the groups that received only one dose (Group 3: HI titer 1:202; MN titer 1:101; IgG titer 1:13800; Group 5: HI titer 1:1016; MN titer 1:359; IgG titer 1:17644). In comparing the antibody titers detected at the same time, we observed that the second boost significantly increased the immune response (Group 3 vs. Group 5 HI titer, $p<0.001$; $\mathrm{MN}$ titer, $p=$ 0.003; IgG titer, $p=0.172$; Group $4 v s$. Group 6 HI titer, $p=0.004 ; \mathrm{MN}$ titer, $p<0.001$; IgG titer, $p=0.008)$. From the above results, we also noted that the peak mean antibody titers were dramatically improved by the addition of the MF59 adjuvant. It is a pity that neither the second dose nor the addition of the MF59 adjuvant failed to boost the antibody responses into the fourth month or prevent the depletion of the responses at sixth months.

\section{Cellular immune responses in each experimental group}

Figure 2 shows the systemic levels of cytokines at different detection time points in the serum. The cytokines IL-4, IL-5, and IL-10 were produced primarily by Th2 cells. There were also low, but detectable levels of IL-5 and IL-10 in the serum. Vaccination triggered the greatest concentration of IL-4 in the two-dose H7N9+MF59 group $(p<0.001)$; however, there was no statistical difference between the other five groups $(p=0.19)$. Similarly, there was no statistical difference in the levels of IL-5 among all these groups $(p=0.277)$. While IL- 4 was below the detection limit $(1.57 \mathrm{pg} / \mathrm{mL})$ the level of all three cytokines increased following viral challenge. Levels of IL-4, IL-5, and IL-10 were the greatest in the two-dose H7N9+MF59 group (Group 6) among all experimental groups following viral challenge (IL-4, $p=0.003$; IL-5, $p=0.006$; and IL- 
$10 p<0.001)$. The addition of the MF59 adjuvant to the vaccine resulted in a substantial increase in Th2 cytokine production after virus inoculation (IL-4, $p=0.001$; IL-5 $p=0.044$; and IL-10 $p=0.014$ ). In contrast, the levels were not statically different between the one-dose groups (Groups 3 and 5) and the two-dose groups (Groups 4 and 6) following viral challenge (IL-4, $p=0.511$; IL-5, $p=$ 0.311 ; IL-10, $p=0.222$ ).

The cytokines IFN- $\gamma$ and IL-2 are primarily produced by Th1 cells. Low level secretion of the above two cytokines was maintained throughout the period following immunization. The addition of the MF59 adjuvant to the vaccine (Groups 5 and 6) resulted in remarkable changes to the level of IL-2 following viral challenge $(p=0.044)$, but also resulted in lower levels of IFN- $\gamma$ production following viral challenge
( $p=0.524)$. GM-CSF is mainly secreted by activated macrophages, activated T cells, and endothelial cells [13, 14]. Surprisingly, the viral challenge resulted in a sharp decline in the GM-CSF response, which remained at high levels before the viral challenge. There was no significant difference among the six groups $(p=0.546)$.

The $\mathrm{CD}^{+} / \mathrm{CD}^{+}$ratio of splenocytes was quantified (Figure 3A) and found to increase in the groups treated with the MF59 adjuvant (Groups 5 and 6) compared with the other groups (Groups $1-4)(p<0.001)$; however, there were no significant differences in the $\mathrm{CD}^{+} / \mathrm{CD}^{+}$ ratios between the groups that received the H7N9 antigen without the adjuvant (Groups 3 and 4) and those that received the blank and PBS controls $(p=0.689)$ (Figure $3 \mathrm{~B})$. In conjunction with the cytokine profile, the MF59 adjuvant was associated with a significant accumulation

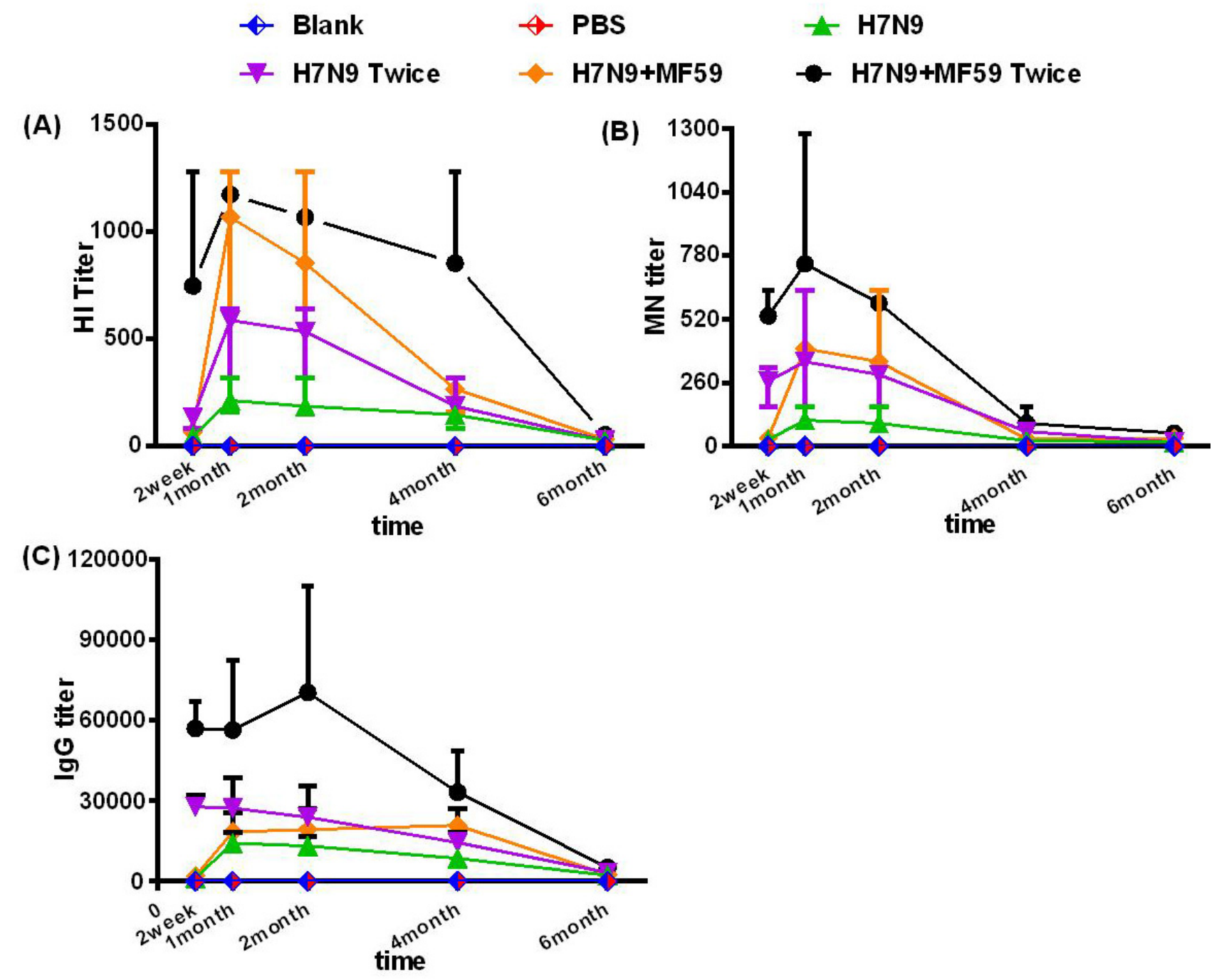

Figure 1: Measurements of the antibody responses. A. HI antibodies, B. MN antibodies, and $\mathbf{C}$. IgG responses of all six groups measured at two weeks, and one, two, four, and six months after the last immunization. Each dot represents the geometric mean titer. Each mouse was intramuscularly injected with various immune formulations: Groups 1 and 2 were treated with nothing and PBS, respectively; Groups 3 and 4 were immunized with one dose $3 \mu \mathrm{g}$ HA and one dose $3 \mathrm{ug}$ HA plus $0.05 \mathrm{~mL}$ MF59, respectively; Groups 4 and 6 were immunized with two doses of $3 \mu \mathrm{g}$ HA and two doses $3 \mu \mathrm{g}$ HA plus $0.05 \mathrm{~mL}$ MF59, respectively with a two-week interval. 
in $\mathrm{CD}^{+}$splenocytes.

\section{Protective effects of the candidate vaccine}

Even six months after immunizing with the HA antigen (Groups $3-6$ ), the antibody titers were significantly increased following viral challenge (Figure 4). Since the antibody response increased progressively with MF59 (Groups 5 and 6), Groups $3-6$ were compared to evaluate the effects of the MF59 adjuvant (HI titer, $p$ $=0.015 ; \mathrm{MN}$ titer, $p=0.023$; IgG titer, $p=0.045$ ). The comparison between Groups 3 and 5 and Groups 4 and
6 revealed that there was also a substantial impact of a second boost on the antibody response (HI titer, $p=0.034$; $\mathrm{MN}$ titer, $p=0.023$; IgG titer, $p=0.008$ ).

We observed lethargy, rough hair, and a loss of appetite in all six experimental groups after wide type H7N9 challenge but no deaths. Figure 5 presents the viral titers in the lungs one week after H7N9 viral challenge, for which a second boost was found to reduce the viral titers compared with the groups immunized once with no statistical difference $(p=0.456)$. Moreover, the immunogenicity generated in reponse to H7N9 antigen was more effective when paired MF59 adjuvant $(p=$ $0.045)$.
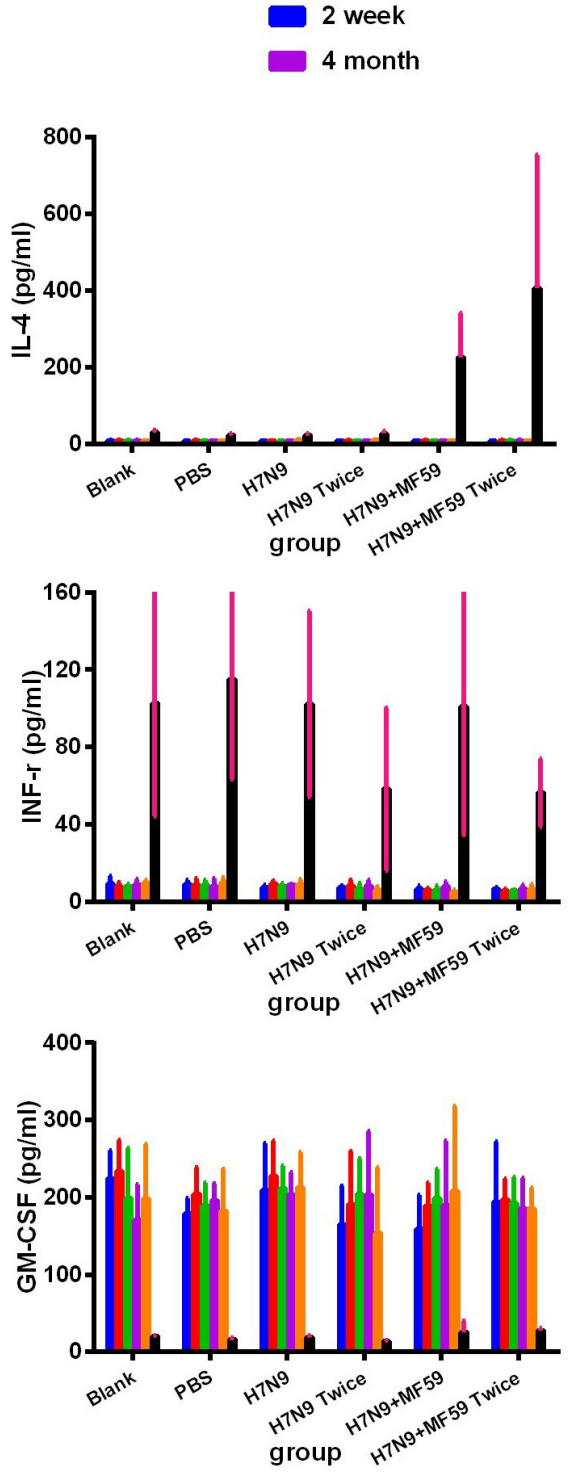

1 month

6 month
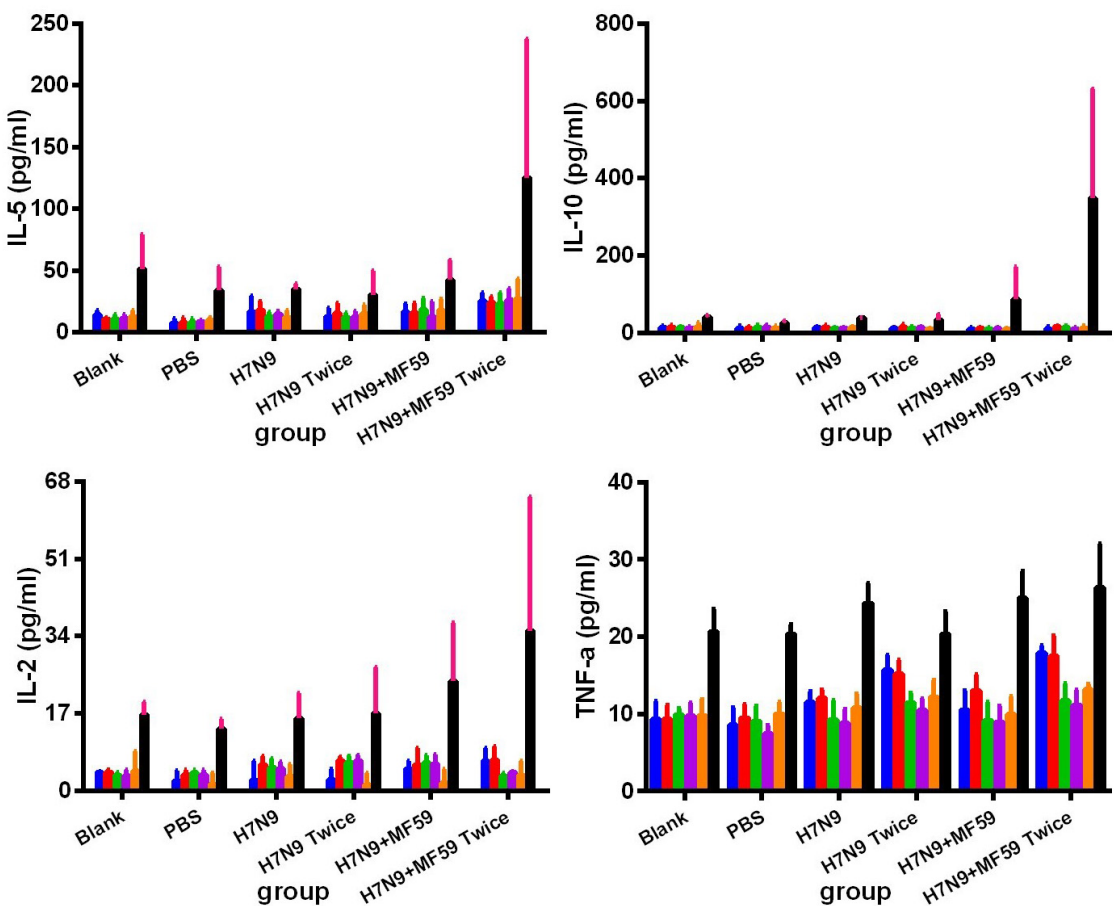

Figure 2: Systemic expression of Th1 (IFN- $\gamma$ and IL-2), Th2 (IL-4, IL-5, and IL-10) and other cytokines (TNF- $\alpha$ ) in experimental groups. Group 1 (Blank), Group 2 (PBS), Group 3 (one dose $3 \mu \mathrm{g} \mathrm{HA),} \mathrm{Group} 4$ (one dose $3 \mu \mathrm{g}$ HA plus $0.05 \mathrm{~mL}$ MF59), Group 5 (two doses $3 \mu \mathrm{g} \mathrm{HA}$ ), and Group 6 ( 2 doses $3 \mu \mathrm{g}$ HA plus $0.05 \mathrm{~mL}$ MF59), as measured using a multiplex Luminex LiquiChip. The cytokine expression profiles were measured in the serum of $\mathrm{BALB} / \mathrm{c}$ mice at two weeks, one, two, four, and six months after the last immunization, and one week after viral challenge. 

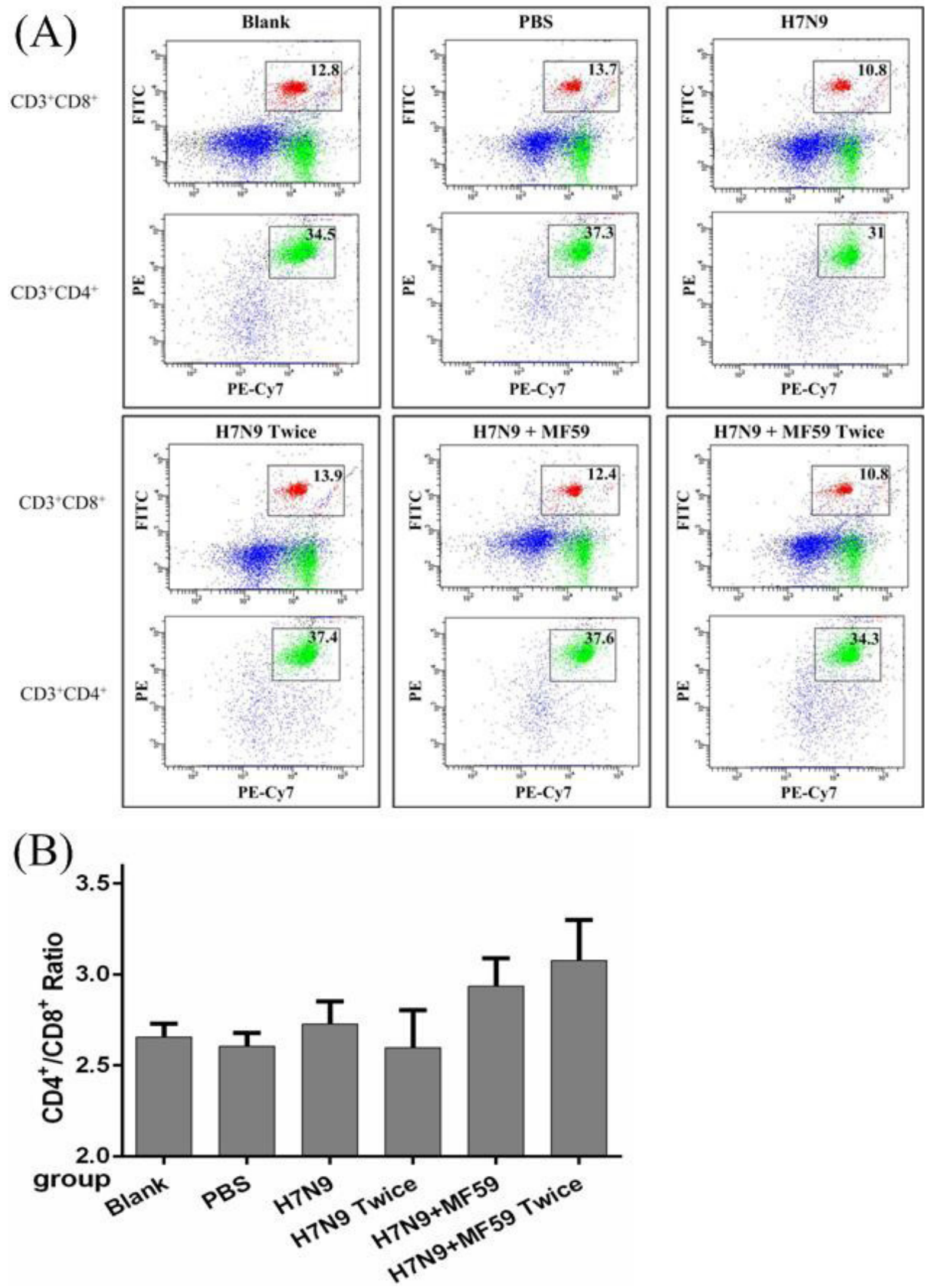

Figure 3: The spenocyte subpopulations of $\mathrm{CD3}^{+}, \mathrm{CD}^{+}$, and $\mathrm{CD8}^{+}$cells in each group. Mice were vaccinated with nothing, PBS, one dose $3 \mu \mathrm{g}$ HA, one dose $3 \mu \mathrm{g}$ HA plus $0.05 \mathrm{~mL}$ MF59, two doses $3 \mu \mathrm{g}$ HA and two doses $3 \mathrm{ug}$ HA plus $0.05 \mathrm{~mL}$ MF59 two weeks after last dose. A. Splenocytes were divided into subpopulations based on the surface expression of $\mathrm{CD} 3{ }^{+} \mathrm{CD} 4^{+}\left(\mathrm{T}\right.$ helper cells), $\mathrm{CD} 3{ }^{+} \mathrm{CD} 8^{+}$ (cytotoxic T cells). B. The $\mathrm{CD} 4^{+} / \mathrm{CD} 8^{+}$ratio in each of the six groups. 


\section{Histopathological analysis of the H7N9 vaccine with or without adjuvant}

Two weeks after the final immunization, no inflammatory reactions or other histopathological changes were observed in any of the tissues, including the heart, liver, lung, kidney, stomach, brain, bone, and intestines (data not shown). Immunization with the influenza vaccine with adjuvant (Figure 6A) caused mixed cell infiltration in the interstitium of the intramuscular injection sites. We also observed lymphoid hyperplasia in the follicles and plasmacytosis in the popliteal lymph nodes (Figure 6B). The popliteal lymph node was the local draining lymph node for the injection site, and these changes were expected following vaccine delivery. Extramedullary hematopoiesis in the spleen (Figure 6C) was also observed. This change was considered to be an adaptive response to the inflammatory reaction incited by the injection of the adjuvant. Six months after the last immunization, only mononuclear cell infiltration and fibroplasias at the injection sites (Figure 6D), as well as lymphoid hyperplasia and plasmacytosis in the popliteal lymph nodes (Figure 6E) were noted; albeit most of the changes had resolved.

\section{DISCUSSION}

Studies have established the great significance of vaccination for mitigating an influenza pandemic [15]. For influenza viruses, highly efficient reverse genetics systems that allow the generation of desired reassortants from cloned cDNA directly are now available $[16,17]$. This process can remove major molecular features that
(A)

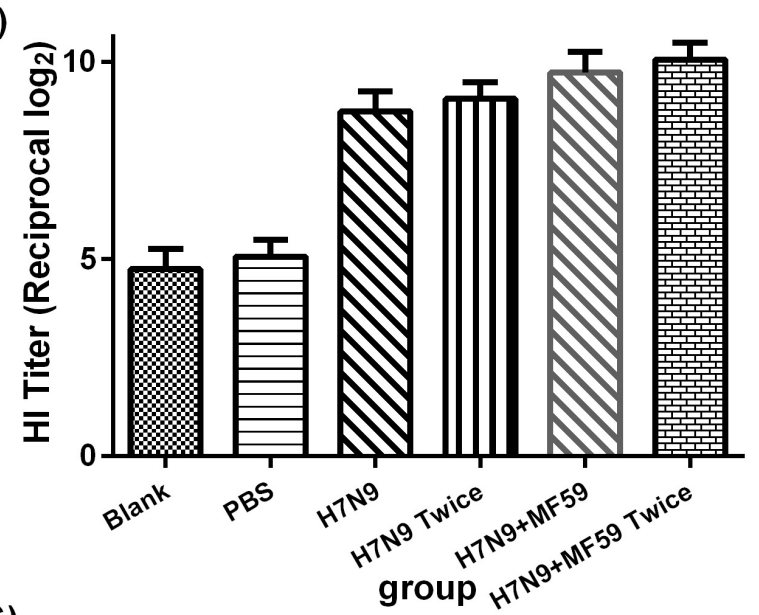

(C)

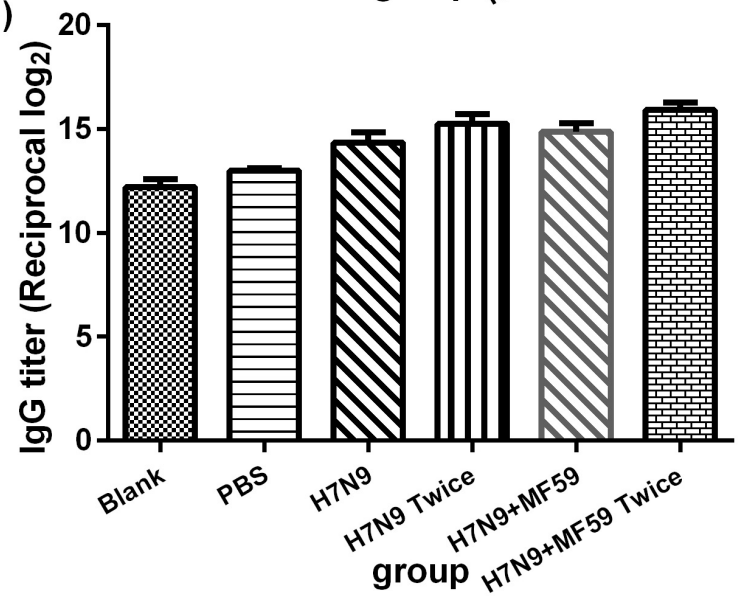

PBS $\mathbf{\Delta ~ H 7 N 9}$ H7N9+MF59 H7N9+MF59 Twice

(B)

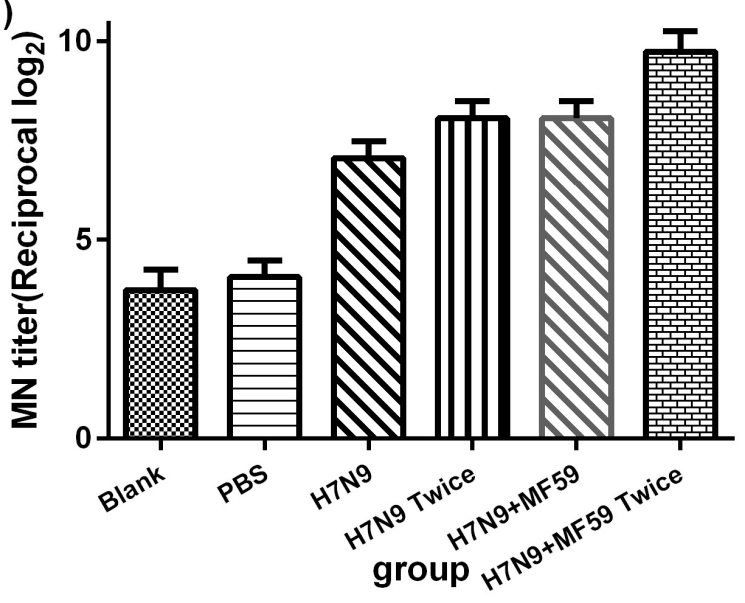

Figure 4: Antibody responses, including A. HI antibodies, B. MN antibodies, and C. IgG titers, for groups of mice one week after viral challenge. Each dot represents the geometric mean titer obtained from groups of six mice. The mice were intramuscularly injected with various immune formulations: Groups 1 and 2 were treated with nothing and PBS, respectively. Groups 3 and 4 were immunized with one dose $3 \mu \mathrm{g} \mathrm{HA}$, one dose $3 \mu \mathrm{g}$ HA plus $0.05 \mathrm{~mL}$ MF59, respectively; Groups 4 and 6 were immunized with two doses $3 \mu \mathrm{g}$ HA and two doses $3 \mu \mathrm{g}$ HA plus $0.05 \mathrm{~mL}$ MF59, respectively with a two-week interval. Six months after the last immunization, the mice in each group were intranasally inoculated with $50 \mu \mathrm{L} 10^{6} \mathrm{TCID}_{50}$ wild type H7N9 virus A/Zhejiang/DTID-ZJU01/2013 (H7N9). 
confer high virulence, which is particularly useful for the highly pathogenic $\mathrm{H} 5$ or $\mathrm{H} 7$ strains and can be an asset for the rapid preparation of vaccine strains. Our "six plus two" reassorted vaccine seed (the HA and NA gene segments of the A/Zhejiang/DTID-ZJU01/2013 virus on a PR8 genetic background) was produced using eight individual plasmid transfection system. We have demonstrated the low virulence and transmissibility of this strain, indicating that it is suitable for use as an ideal influenza vaccine seed strain. Moreover, this vaccine seed can be parenterally administered in an inactive form to produce the split vaccine. Most H7N9 vaccines are developed based on the A/Shanghai/2/2013 and A/Anhui/1/2013 strains. The A/Zhejiang/1/2013 strain was the first to be used in our split vaccine. The inadequacy of split vaccines is low immunogenicity, because these HAs are poor vaccine antigens [18]. Thus, adjuvants must be employed to augment the immune response to split vaccines. The
MF59 emulsion first gained approval for human use in 1997, and was subsequently approved in 23 countries for use as a part of the influenza vaccine for elderly subjects. A previous large-scale analysis supported the good safety profile and the associated substantial immunogenicity $[11,19]$. A histopathological examination in this study also demonstrated that the MF59 adjuvant may stimulate a more severe but local and recoverable inflammatory response, which may be related to its strong potentant immune stimulatory effects. We also confirmed that MF59 exerted a more robust response when paired with this split vaccine compared with the most traditional alum adjuvant [20].

In the absence of any established standard of protection to avian influenza, a good correlation was shown between $\mathrm{MN}$ titers $\geq 80$. The analysis of the sera from patients who recovered from an avian influenza infection also supports the $\mathrm{MN}$ titer $\geq 1: 80$ as potential

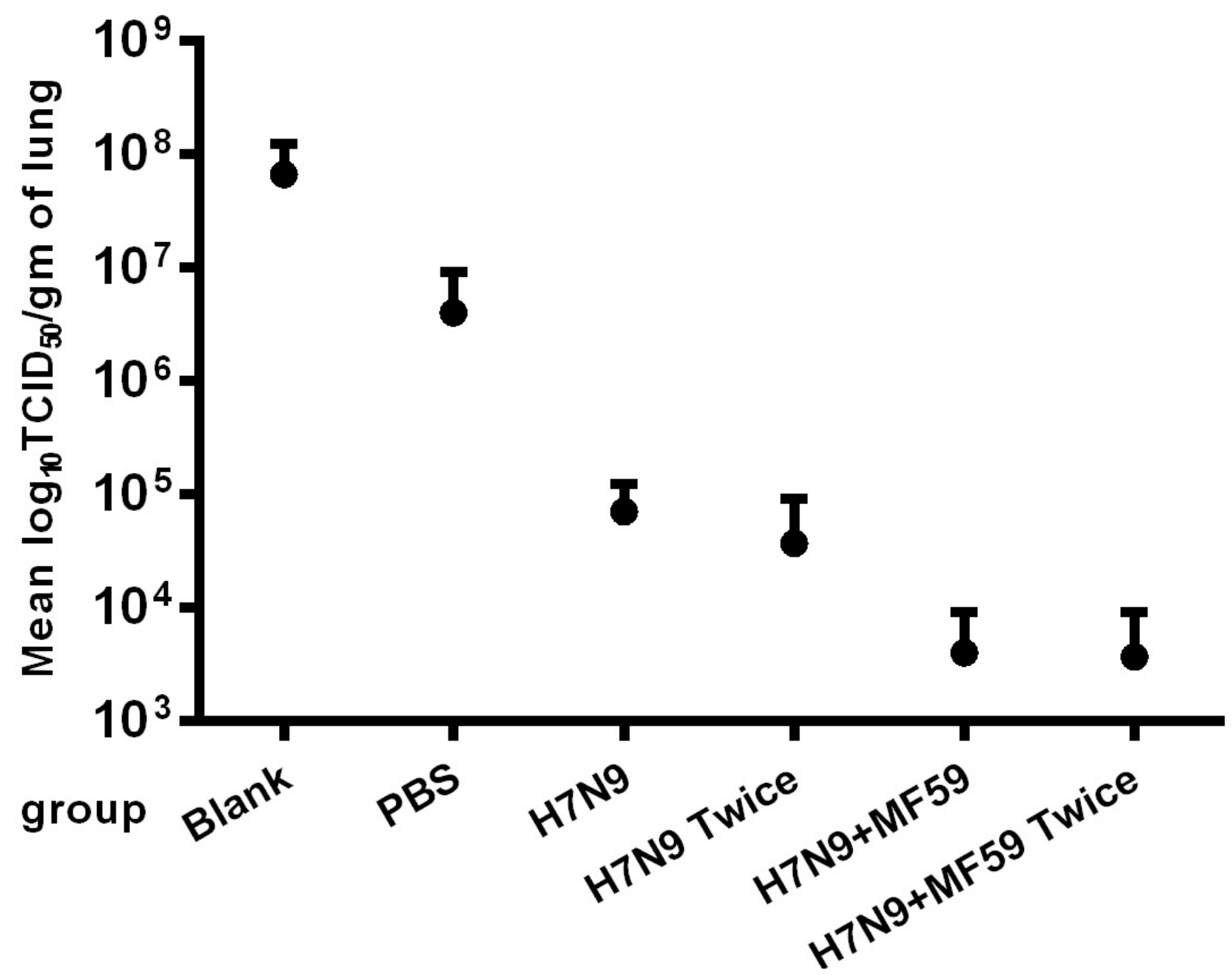

Figure 5: Virus titers in the lungs one week after the H7N9 viral challenge. Replications of the H7N9-WT challenged viruses one week after viral challenge in the lungs of immunized BALB/c mice were determined using the $\mathrm{TCID}_{50}$ method in MDCK cells. Virus titers in lungs are expressed as the means $\pm \mathrm{SE}$ of the $\log _{10} \mathrm{TCID}_{50}$ per $\mathrm{g}$ of tissue. 
(A) injection sites

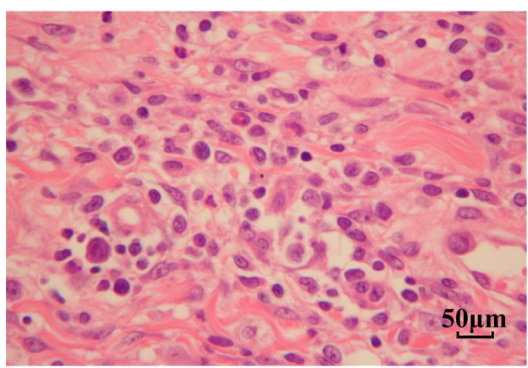

(D) injection sites

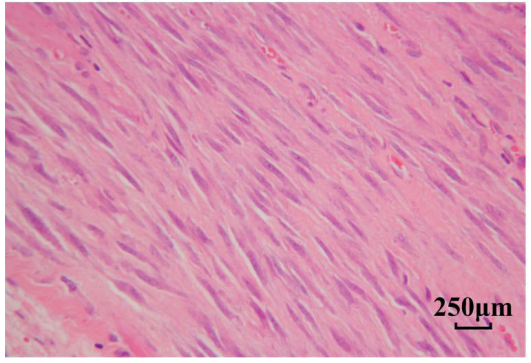

(B) popliteal lymph nodes

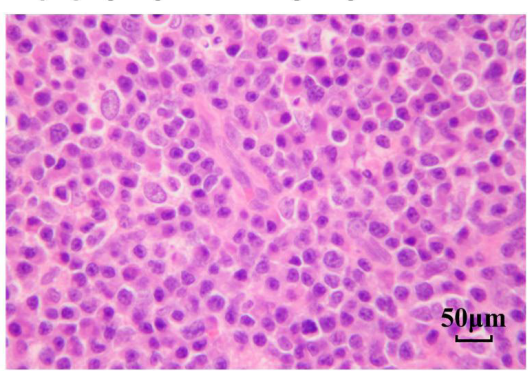

(E) popliteal lymph nodes

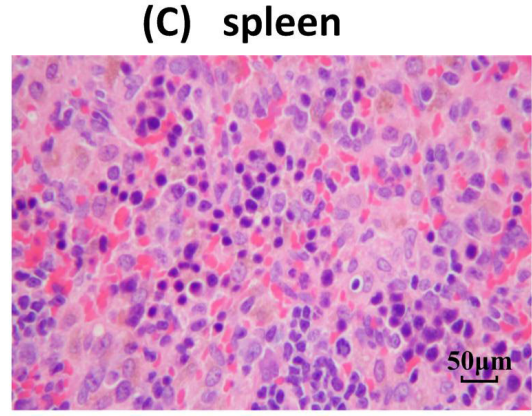

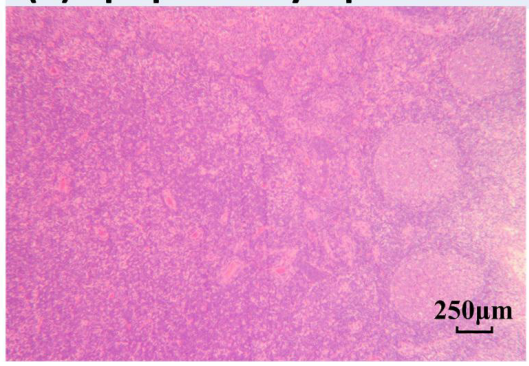

Figure 6: Histological analysis of various tissues. H\&E staining was performed on sections of various organs from mice immunized with the H7N9 vaccine with the MF59 adjuvant. A.-C. Two weeks after the last immunization (original magnification $\times$ 200). A. Intramuscular injection sites, B. popliteal lymph nodes, and C. spleen. D.-E. Six months after the last immunization (original magnification $\times 40$ ). D. Intramuscular injection sites and E. popliteal lymph nodes.

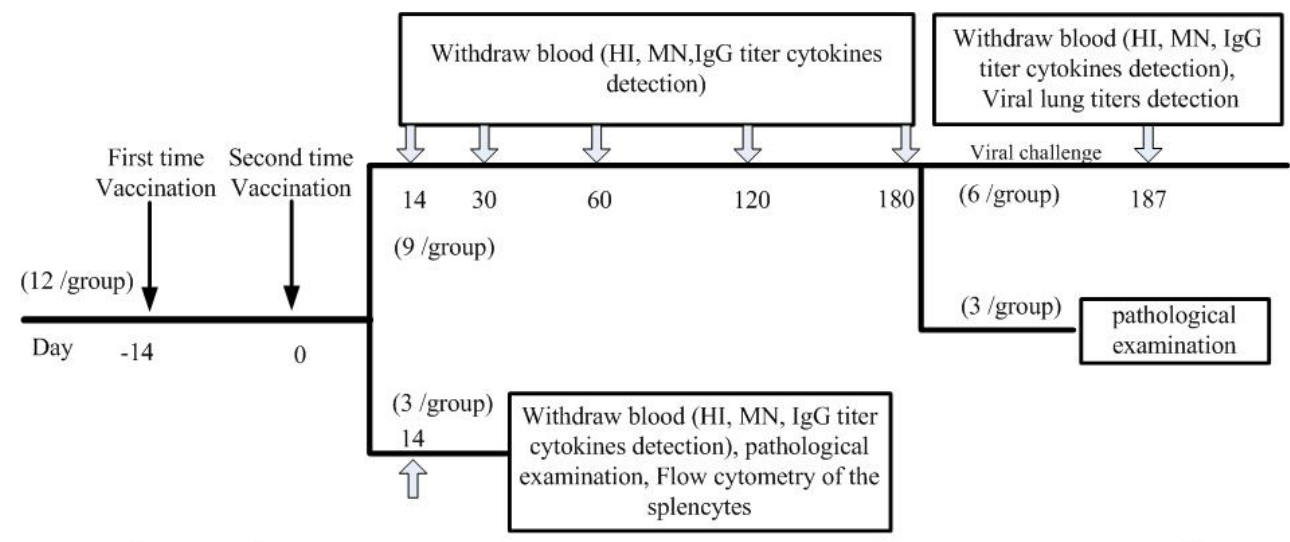

\begin{tabular}{|c|c|c|c|}
\hline \multirow{2}{*}{$\begin{array}{c}\text { Group } \\
\text { No. }\end{array}$} & \multirow{2}{*}{$\begin{array}{l}\text { Group } \\
\text { Name }\end{array}$} & \multicolumn{2}{|c|}{ Vaccine substances } \\
\hline & & First time Vaccination & Second time Vaccination \\
\hline 1 & BLANK & - & - \\
\hline 2 & PBS & - & PBS $100 \mu \mathrm{L}$ \\
\hline 3 & H7N9 & - & H7N9 $(3 \mu \mathrm{g} \mathrm{HA})$ \\
\hline 4 & H7N9 Twice & H7N9 $(3 \mu \mathrm{g} \mathrm{HA})$ & H7N9 $(3 \mu \mathrm{g} \mathrm{HA})$ \\
\hline 5 & H7N9 + MF59 & - & $\begin{array}{c}\text { H7N9 + MF59 } \\
(3 \mu \mathrm{g} \mathrm{HA}+0.05 \text { mL MF59) }\end{array}$ \\
\hline 6 & $\begin{array}{c}\text { H7N9 + MF59 } \\
\text { Twice }\end{array}$ & $\begin{array}{c}\text { H7N9 + MF59 } \\
(3 \mu \mathrm{g} \mathrm{HA}+0.05 \mathrm{~mL} \text { MF59) }\end{array}$ & $\begin{array}{c}\text { H7N9 + MF59 } \\
(3 \mu \mathrm{HA}+0.05 \mathrm{~mL} \text { MF59) }\end{array}$ \\
\hline
\end{tabular}

Figure 7: Flow chart (top) and table (bottom) of experimental design. Arrows “ $\downarrow$ ” indicate days of vaccination and Arrows “ $\Downarrow$, , indicate days of sampling. HI: hemagglutinin inhibition; MN: Micro-neutralization; IgG: Immunoglobulin G. 
predictor of clinical benefit [21]. This study confirmed that the vaccination of mice with the two-dose split H7N9 vaccine produced long-lasting antibody titers, with titers (MN titer $\geq 80$ ) persisting for $\geq$ two months in vaccinated mice. Moreover, the addition of MF59 can raise this value to four months. We found that combining the H7N9 antigen with the MF59 adjuvant and a delivering a second dose increased the immugenicity of the vaccine and ultimately the protective efficacy against H7N9 virus six months post-immunization. In addition, despite almost a disapearance of antibodies from the serum samples of vaccinated mice, humoral response including $\mathrm{HI}$ and MN antibodies and IgG titers progressively increased following viral challenge. Furthermore, the histopathology in the lungs also revealed that two doses of the MF59 adjuvanted $\mathrm{H} 7 \mathrm{~N} 9$ vaccine provides substantial protection for at least 6 months.

Helper $\mathrm{T}$ cell $(\mathrm{Th})$ responses can be induced by a particular adjuvant and secrete a spectrum of cytokines [22]. Secretion of IFN- $\gamma$ and IL-2 (a Th1-type response), has been typically associated with CTL and delayedtype hypersensitivity responses. In contrast, Th2-type responses which are characterized by the secretion of IL-4, IL-5, and IL-10 may invoke B cell activation and antibody production [23]. Additionally, it is well established that different adjuvants used in a vaccine can bias either a Th1 or a Th2 response. Low levels of the cytokines IL-4, IL-5, and IL-10 were detected in all six groups at two weeks, and one, two, four, and six months following immunization, this finding may not be surprising given the relatively short half-life of cytokines in mice, presumably due to its rapid clearance by receptormediated uptake. One limitation of this study is that we did not perform a short-term analysis of cytokine changes (in hour increments following immuization) or determine the specific $\operatorname{IgG}$ subclasses that were induced by the vaccine. Following viral challenge, there was a substantial increase in Th-2 cytokines, including IL-4, IL-5 and IL10 , detected in the serum of mice immunized with two doses of the MF59 adjuvant H7N9 split vaccine. These findings indicate that the MF59 adjuvant-induced serum cytokine profiles are consistent with a primarily Th2type response and a second dose can boost this effect. In addition, we found that adding MF59 to the split vaccine caused a reduction in the IFN- $\gamma$ response and an increase in the IL-2 response following the viral challenge, which is consistent with previous results indicating that MF59 adjuvants are poor inducers of Th1 responses [23]. Th2type responses reported to invoke a humoral immune response and were consistent with the production of antibodies, while high concentrations of IFN- $\gamma$ and can be generally immunosuppressive and most Th1 clones are directly cytotoxic for activated B cells and antibody production [24]. Moreover, $\mathrm{CD}^{+}$cells haves been shown to be beneficial for the early clonal expansion of B cells and for the generation and memory B cells [25, 26], and recent advances have suggested a close association between $\mathrm{CD}^{+} \mathrm{T}$ cell and antibody responses [27]. Thus, in conjunction with the observed cytokine profile, we verified that MF59 can promote CD4+ activation.

In conclusion, a monovalent $\mathrm{H} 7 \mathrm{~N} 9$ split vaccine was manufactured based on the A/Zhejiang/1/2013 strain using reverse genetics. All previously published articles regarding H7N9 vaccines have evaluated only the shortterm efficacy over duration of a few weeks [28, 29]. In this study, we prolonged the observation to six months and carried out this preclinical experiment in a relatively comprehensive and systematic manner. We observed antibody fluctuation and changes in the levels of serum cytokines in the six months following immunization, and subsequently evaluated the protective efficacy and possible immune mechanisms of the vaccine. In mice immunized with the H7N9 split vaccine, both antibody production and Th2 responses were strongly boosted by the MF59 adjuvant and a second dose. Such responses may be strongly associated with activation of the Th2 response as two doses of the MF59 adjuvant H7N9 split vaccine were found to elicit protective antibody responses which persisted for at least four months, and protected mice from subsequent Zhejiang virus challenge as long as six months after immunization. In addition, MF59 was able to stimulate endogenous $\mathrm{CD}^{+} \mathrm{T}$ cell activation.

\section{MATERIALS AND METHODS}

Six to seven-week-old female BALB/c mice were purchased from Joint Ventures SIPPER-BK Experimental Animal Co. (Shanghai, China). All animal studies were performed in accordance with the Guide for the Care and Use of Laboratory Animals of Zhejiang Province and were approved by the local Ethics Committee. Zhejiang Tianyuan Bio-Pharmaceutical Co., Ltd. (which was affiliated with Novartis Vaccine Inc.) provided the MF59 ${ }^{\mathrm{TM}}$ adjuvant (MF59 is a trade mark of Novartis AG and Affiliate Companies). The Madin-Darby canine kidney cell line (MDCK) was obtained from ATCC (Manassas, VA, USA).

\section{Viruses and vaccines}

The A/Zhejiang/DTID-ZJU01/2013(H7N9) virus was isolated from a patient in Zhejiang province, China in 2013. By transfecting eight individual pHW2000 plasmids into Vero cells [16], we created a A/ZJU01/PR8/2013 vaccine seed strain which harbored HA and NA genes from the aforementioned virus and six internal genes from the PR8 virus, then this reassortant virus was propagated in specific-pathogen-free (SPF) embryonated chicken eggs. The following processes were required before acquiring the split vaccine: clarification, ultrafiltration, zonal centrifugation, purification, cleavage, extinguishing, 
the second- zonal centrifugation, sterile filtration and identification. Finally, the HA content was quantified using one-way immune diffusion.

\section{Animal immunization}

Groups $(n=12)$ of six to seven-week-old female $\mathrm{BALB} / \mathrm{c}$ mice were immunized twice with $100 \mu \mathrm{L}$ of different immune formulations via an intramuscular injection in the hind legs (half dose per injection site; i.e., in each hind leg). As shown in Figure 7, Groups 1 and 2 were treated with nothing and PBS, respectively. Groups $3-6$ were immunized with $3 \mu \mathrm{g}$ HA, $3 \mu \mathrm{g}$ HA, 3 $\mu \mathrm{g}$ HA plus $0.05 \mathrm{~mL}$ MF59, and $3 \mu \mathrm{g}$ HA plus $0.05 \mathrm{~mL}$ MF59, respectively, in $100 \mu \mathrm{L}$ PBS. Groups 2, 4, and 6 were boosted with PBS, $3 \mu \mathrm{g}$ HA and $3 \mu \mathrm{g}$ HA plus 0.05 $\mathrm{mL}$ MF59, respectively by a 2-week interval. All animals were bled via the tail vein the day before immunization, at two weeks, one month, two months, four months, and six months thereafter, and again one week following viral challenge. A lack of pre-existing immunity against the influenza virus was ascertained in all mice (HI activity < 10).

\section{Virus inoculation}

Six months after the last immunization, mice in each group $(n=6)$ were intranasally inoculated with 50 $\mu \mathrm{L} 10^{6} \mathrm{TCID}_{50}$ wild type H7N9 virus A/Zhejiang/DTIDZJU01/2013(H7N9) diluted in PBS. A TCID T0 $_{50}$ assay was performed using the method of Reed and Muench [30]. Mice were observed for illness and death for seven days after infection.

\section{HI test}

All serum samples were treated with receptor destroying enzyme [9]. Prior to HI testing, a two-fold serial dilution series of serum was mixed 1:1 with four hemagglutinating units of virus (wild type H7N9 virus A/Zhejiang/DTID-ZJU01/2013 (H7N9)) and incubated at $37^{\circ} \mathrm{C}$ for $1 \mathrm{~h}$. Subsequently, $50 \mu \mathrm{L} 1 \%$ chicken erythrocytes were added, mixed, and incubated for $1 \mathrm{~h}$ at $4^{\circ} \mathrm{C}$; all agglutination patterns were read within $10 \mathrm{~min}$.

\section{MN assay}

MDCK cells were seeded at a density of $2 \times 10^{4}$ cells/well in 96-well plates and cultured to $80 \%-90 \%$ confluency at $37^{\circ} \mathrm{C}$. Heat-inactivated serum samples were diluted 1:10 with DMEM, subjected to a two-fold serial dilution, and mixed with $50 \mu \mathrm{L}$ of $10^{6} \mathrm{TCID}_{50} \mathrm{~A} / \mathrm{Zhejiang} /$ DTID-ZJU01/2013(H7N9) virus for $1 \mathrm{~h}$ at $37^{\circ} \mathrm{C}$. Cells were incubated in the presence of TPCK-treated trypsin at $37^{\circ} \mathrm{C}$ for $72 \mathrm{~h}$ post-infection. Cell supernatants were then harvested and transferred to V-bottom 96-wells plates. The presence of virus was detected using a hemagglutination assay.

\section{Immunoglobulin $\quad G \quad$ enzyme-linked immunosorbent assay (IgG-ELISA)}

All 96-wells of polyvinyl chloride microtiter plates (Falcon, USA) were coated overnight at $4^{\circ} \mathrm{C}$ with $100 \mathrm{ng}$ / well HA antigen in a PBS coating solution (KPL, USA). At room temperature, the wells were coated with $1 \%$ bovine serum albumin (Sigma-Aldrich, USA) and incubated for $2 \mathrm{~h}$ after three washes. Next, the wells were washed and two-fold serial dilutions of serum were inoculated in $100 \mu \mathrm{L}$ volumes for $1 \mathrm{~h}$. The plates were washed once again, and $100 \mu \mathrm{L}$ peroxidase-labeled rabbit anti-mouse immunoglobulin G (Zymed, USA) was added to each well and incubated for $2 \mathrm{~h}$. After another wash, $100 \mu \mathrm{L} /$ well substrate TMB (Sigma) was added and the reaction was subsequently stopped. Absorbance was measured at 450 $\mathrm{nm}$. ELISA titers were expressed as reciprocal dilutions and yielded an OD that was higher than the average OD of the blanks plus three times the SD.

\section{Immunoassay-luminex measurement}

Serum samples were measured using multiplex bead assays (\#M6000003J7, Bio-Rad; USA) incorporated into MILLIPLEX MAP panels that were run on a Luminex 200 instrument. All samples were thawed on ice, vortexed, centrifuged at $14,000 \times g$ for $10 \mathrm{~min}$ at $4^{\circ} \mathrm{C}$, diluted $1: 4$, followed by vortexing of all bead-antibody complexes. To each well, $50 \mu \mathrm{L}$ of bead-antibody complexes was added and then washed followed by the addition of either $50 \mu \mathrm{L}$ of the standard, controls, or samples. Plates were incubated at room temperature for $30 \mathrm{~min}$ with constant agitation, then washed three times and incubated for 30 min with $25 \mu \mathrm{L}$ biotinylated detection antibody. Next, the plate was washed and $50 \mu \mathrm{L}$ streptavidin-PE was added to the detection antibody for another $10 \mathrm{~min}$. Finally, plates were washed and the beads were suspended in $125 \mu \mathrm{L}$ assay buffer. For analysis, the 96-well plate was placed in a BioPlex reader and the data collection, analysis, and quality control were performed as previously described by Lovestone [31].

\section{Flow cytometry of the splenocytes}

Spleens were aseptically removed from the mice two weeks after the last immunization and gently dissociated through a stainless-steel sieve into RPMI medium supplemented with $5 \%$ fetal calf serum, and collected by pelleting at 1, $200 \mathrm{rpm}$ in a Beckman GPKR 
centrifuge. Erythrocytes were lysed for $1 \mathrm{~min}$ in $155 \mathrm{mM}$ $\mathrm{NH} 4 \mathrm{Cl}-17 \mathrm{mM}$ Tris-HCl (pH 7.2). The cell number was determined in a Neubauer chamber.

Splenocytes were studied by a standard protocol for analysis via flow cytometry. Suitable amounts of conjugated monoclonal antibodies against $\mathrm{CD}^{+} / 4^{+} / 8^{+}$ were added to $0.1 \mathrm{~mL}$ splenocytes and incubated for $30 \mathrm{~min}$ at room temperature. Preparations were then washed and fixed using the FACS lysing solution (Becton Dickinson Immunocytometry System, Mountain View, CA, USA). The following combinations of monoclonal antibodies were used: $\mathrm{PE}-\mathrm{Cy}^{\mathrm{TM}} 7-\mathrm{CD}^{+}, \mathrm{PE}^{+} \mathrm{CD} 4^{+}$and FITC-CD8 ${ }^{+}$(BD PharMingen, San Diego, CA) for recognizing $\mathrm{T}$ lymphocytes, $\mathrm{T}$ helper, and cytotoxic $\mathrm{T}$ lymphocytes, respectively.

\section{Virus titers of lung tissues}

Viral lung titers were determined using 10-fold serial dilutions of tissue extracts, and were tested for infectivity of MDCK cells in 96-well plates after $48 \mathrm{~h}$ incubation. Viral titers were estimated based on the method of Reed and Muench.

\section{Analysis of vital organs by histopathology}

All vital organs, including the heart, liver, spleen, lung, kidney, stomach, brain, bone, intestines, popliteal lymph node, and injection site of three mice from each group were harvested at two weeks and six months after the last immunization. After the tissues were fixed and embedded in paraffin wax, 4- $\mu \mathrm{m}$ thick sections were prepared, stained with $\mathrm{H} \& \mathrm{E}$, and examined microscopically.

\section{Statistical analysis}

Statistical analyses of the data for HI, antibody, and viral titers were performed with SPSS software (SPSS Inc., USA) using a two-way ANOVA test with a Turkey post-hoc assessment. Values represent the means \pm SEM for the indicated sample sizes. A threshold of $p<0.05$ was used to denote statistical significance.

\section{Abbreviations}

HA: hemagglutinin; NA: neuraminidase; DMEM: Dulbecco modified Eagle medium; HI: hemagglutinin inhibition; MN: Micro-neutralization; IgG: Immunoglobulin G; SPF: specific-pathogen-free; PR8: A/ PuertoRico/8/34(H1N1); H7N9: avian influenza A (H7N9)

\section{Author contributors}

Conceived and designed the experiments: H. Yao, L. Li, N. Wu and H. Chen. Performed the experiments: H. Ou, D. Yu, T. Weng, F. Wang, X. Wu, L. Cheng. Analyzed the data: $\mathrm{H}$. Wu, X. Lu. Wrote the first draft of the manuscript: H. Yao, H. Ou. Provided H7N9 vaccine and MF59 adjuvant: W. Yao. All authors read and approved the final manuscript.

\section{CONFLICTS OF INTEREST}

The author has declared that the following interests are relevant to the submitted work. Wei Yao is employees of Zhejiang Tianyuan Bio-Pharmaceutical Co., Ltd. (which was affiliated with Novartis Vaccine Inc.). He participated in the production of the H7N9 vaccine and MF59 adjuvant but had nothing to do with the investigation of the immunogenicity and bioactivities of this vaccine. The other authors declare no competing interests.

\section{FUNDING}

This work was supported by grants from the State Project For Essential Drug Research and Development (\#2015ZX09101044), and the Science \& Technology Key Program of Zhejiang China (\#2014C03039).

\section{REFERENCES}

1. Gao R, Cao B, Hu Y, Feng Z, Wang D, Hu W, Chen J, Jie Z, Qiu H, Xu K, Xu X, Lu H, Zhu W, et al. Human infection with a novel avian-origin influenza A (H7N9) virus. N Engl J Med. 2013; 368: 1888-1897.

2. World Health Organization. Human infection with avian influenza A (H7N9) virus-China. Available at: http://www. who.int/csr/don/23-may-2017-ah7n9-china/en/

3. To KK, Chan JF, Yuen KY. Viral lung infections: epidemiology, virology, clinical features, and management of avian influenza A (H7N9). Curr Opin Pulm Med. 2014; 20: 225-232.

4. Cox RJ, Madhun AS, Hauge S, Sjursen H, Major D, Kuhne M, Hoschler K, Saville M, Vogel FR, Barclay W, Donatelli I, Zambon M, Wood J, et al. A phase I clinical trial of a PER.C6 cell grown influenza H7 virus vaccine. Vaccine. 2009; 27: 1889-1897.

5. Couch RB, Patel SM, Wade-Bowers CL, Nino D. A randomized clinical trial of an inactivated avian influenza A (H7N7) vaccine. PLoS One. 2012; 7: e49704.

6. Rudenko L, Kiseleva I, Naykhin AN, Erofeeva M, Stukova M, Donina S, Petukhova G, Pisareva M, Krivitskaya V, Grudinin M, Buzitskaya Z, Isakova-Sivak I, Kuznetsova $\mathrm{S}$, et al. Assessment of human immune responses to $\mathrm{H} 7$ 
avian influenza virus of pandemic potential: results from a placebo-controlled, randomized double-blind phase I study of live attenuated H7N3 influenza vaccine. PLoS One. 2014; 9: e87962.

7. Neumann G, Kawaoka Y. Reverse genetics systems for the generation of segmented negative-sense RNA viruses entirely from cloned cDNA. Curr Top Microbiol Immunol. 2004; 283: 43-60.

8. Neumann G, Fujii K, Kino Y, Kawaoka Y. An improved reverse genetics system for influenza A virus generation and its implications for vaccine production. Proc Natl Acad Sci U S A. 2005; 102: 16825-16829.

9. Ou H, Yao W, Wu N, Wang FX, Weng T, Han C, Lu X, Yu D, Wu H, Cheng L, Chen H, Yao H, Li L. Preclinical evaluation of the safety and pathogenicity of a live attenuated recombinant influenza A (H7N9) seed strain and corresponding MF59-adjuvanted split vaccine. Oncotarget. 2016; 7: 81012-81025. https://doi.org/10.18632/ oncotarget. 12746

10. Domnich A, Arata L, Amicizia D, Puig-Barbera J, Gasparini R, Panatto D. Effectiveness of MF59-adjuvanted seasonal influenza vaccine in the elderly: A systematic review and meta-analysis. Vaccine. 2017; 35: 513-520.

11. Clark TW, Pareek M, Hoschler K, Dillon H, Nicholson KG, Groth N, Stephenson I. Trial of 2009 influenza A (H1N1) monovalent MF59-adjuvanted vaccine. N Engl J Med. 2009; 361: 2424-2435.

12. Bernstein DI, Edwards KM, Dekker CL, Belshe R, Talbot HK, Graham IL, Noah DL, He F, Hill H. Effects of adjuvants on the safety and immunogenicity of an avian influenza H5N1 vaccine in adults. J Infect Dis. 2008; 197: 667-675.

13. Tobler A, Gasson J, Reichel H, Norman AW, Koeffler HP. Granulocyte-macrophage colony-stimulating factor. Sensitive and receptor-mediated regulation by 1,25-dihydroxyvitamin D3 in normal human peripheral blood lymphocytes. J Clin Invest. 1987; 79: 1700-1705.

14. Thorens B, Mermod JJ, Vassalli P. Phagocytosis and inflammatory stimuli induce GM-CSF mRNA in macrophages through posttranscriptional regulation. Cell. 1987; 48: 671-679.

15. Ferguson NM, Cummings DA, Fraser C, Cajka JC, Cooley PC, Burke DS. Strategies for mitigating an influenza pandemic. Nature. 2006; 442: 448-452.

16. Hoffmann E, Neumann G, Kawaoka Y, Hobom G, Webster RG. A DNA transfection system for generation of influenza A virus from eight plasmids. Proc Natl Acad Sci U S A. 2000; 97: 6108-6113.

17. Neumann G, Watanabe T, Ito H, Watanabe $\mathrm{S}$, Goto H, Gao P, Hughes M, Perez DR, Donis R, Hoffmann E, Hobom G, Kawaoka Y. Generation of influenza A viruses entirely from cloned cDNAs. Proc Natl Acad Sci U S A. 1999; 96: 9345-9350.

18. Atmar RL, Keitel WA, Patel SM, Katz JM, She D, El
Sahly H, Pompey J, Cate TR, Couch RB. Safety and immunogenicity of nonadjuvanted and MF59-adjuvanted influenza $\mathrm{A} / \mathrm{H} 9 \mathrm{~N} 2$ vaccine preparations. Clin Infect Dis. 2006; 43: 1135-1142.

19. Cheong HJ, Song JY, Heo JY, Noh JY, Choi WS, Park DW, Wie SH, Kim WJ. Immunogenicity and safety of the influenza A/H1N1 2009 inactivated split-virus vaccine in young and older adults: MF59-adjuvanted vaccine versus nonadjuvanted vaccine. Clin Vaccine Immunol. 2011; 18: 1358-1364.

20. Ou H, Yao H, Yao W, Wu N, Wu X, Han C, Cheng L, Chen K, Chen H, Li L. Analysis of the immunogenicity and bioactivities of a split influenza A (H7N9) vaccine mixed with MF59 adjuvant in BALB/c mice. Vaccine. 2016; 34 : 2362-2370.

21. Eichelberger M, Golding H, Hess M, Weir J, Subbarao K, Luke CJ, Friede M, Wood D. FDA/NIH/WHO public workshop on immune correlates of protection against influenza A viruses in support of pandemic vaccine development, Bethesda, Maryland, US, December 10-11, 2007. Vaccine. 2008; 26: 4299-4303.

22. Sjolander A, Bengtsson KL, Morein B. Kinetics, localization and cytokine profile of $\mathrm{T}$ cell responses to immune stimulating complexes (iscoms) containing human influenza virus envelope glycoproteins. Vaccine. 1997; 15: 1030-1038.

23. Mosmann TR, Coffman RL. TH1 and TH2 cells: different patterns of lymphokine secretion lead to different functional properties. Annu Rev Immunol. 1989; 7: 145-173.

24. Mosmann TR, Coffman RL. Two types of mouse helper $\mathrm{T}$-cell clone Implications for immune regulation. Immunol Today. 1987; 8: 223-227.

25. Allen CD, Okada T, Cyster JG. Germinal-center organization and cellular dynamics. Immunity. 2007; 27 : 190-202.

26. Bernasconi NL, Traggiai E, Lanzavecchia A. Maintenance of serological memory by polyclonal activation of human memory B cells. Science. 2002; 298: 2199-2202.

27. Galli G, Medini D, Borgogni E, Zedda L, Bardelli M, Malzone C, Nuti S, Tavarini S, Sammicheli C, Hilbert AK, Brauer V, Banzhoff A, Rappuoli R, et al. Adjuvanted H5N1 vaccine induces early CD4+ T cell response that predicts long-term persistence of protective antibody levels. Proc Natl Acad Sci U S A. 2009; 106: 3877-3882.

28. Liu YV, Massare MJ, Pearce MB, Sun X, Belser JA, Maines TR, Creager HM, Glenn GM, Pushko P, Smith GE, Tumpey TM. Recombinant virus-like particles elicit protective immunity against avian influenza $\mathrm{A}(\mathrm{H} 7 \mathrm{~N} 9)$ virus infection in ferrets. Vaccine. 2015; 33: 2152-2158.

29. Chen Z, Baz M, Lu J, Paskel M, Santos C, Subbarao K, Jin H, Matsuoka Y. Development of a high-yield live attenuated H7N9 influenza virus vaccine that provides protection against homologous and heterologous $\mathrm{H} 7$ wildtype viruses in ferrets. J Virol. 2014; 88: 7016-7023. 
30. Reed LJ, Muench H. A simple method of estimating fifty percent endpoints. Am J Epidemiol. 1938; 27:493-497.

31. Hye A, Riddoch-Contreras J, Baird AL, Ashton NJ, Bazenet C, Leung R, Westman E, Simmons A, Dobson R, Sattlecker M, Lupton M, Lunnon K, Keohane A, et al. Plasma proteins predict conversion to dementia from prodromal disease. Alzheimers Dement. 2014; 10: 799-807 e2. 